\title{
Diverse behaviour of C-3 enolates derived from configurationally isomeric trimethyl 1-methylcyclohexane-1,2,3-tricarboxylates
}

\author{
S. N. Balasubrahmanyam \\ Saras Kshetra, Machohalli, Bengaluru 560 091, India
}

Configurational relationships among three, $A, B$ and $C$, of the four possible isomers of trimethyl 1methylcyclohexane-1,2,3-tricarboxylate imply that $A$ and $C$ should form a common $C-3$ enolate. While methylation of tritylsodium-formed $\mathrm{A}$ C-3 enolate gives one of the two possible meso forms and $B$ C-3 enolate gives the racemic product, $C$ does not form an enolate. ${ }^{1} H$ NMR-assigned preferred conformations of $A$ and $B$ show that their $\mathrm{C}-3$ enolates form $\mathrm{Na}^{+}$complexes stabilized by the C-1 syn, axial ester group, while the C-1 methyl in $C$ hinders removal of the $C-3$ proton, thus preventing enolate formation. Early treatment of $A$ enolate with methyl iodide leads to one of two possible meso methylated products, while late treatment gives the racemic form, also a product of $B$ methylation. A gradual rise in $\mathrm{C} / \mathrm{A}$ ratio is seen on protonating $\mathrm{A}$ enolate, though only a ring flip is involved, this phenomenon is attributed to the intervention of a slow $\mathrm{Na}^{+}$deand re-complexation process. A unified explanation emerges under the premise that while the methylating agent approaches the enolate from the non-hindered face anti to $\mathrm{Na}^{+}$, the proton is guided by $\mathrm{Na}^{+}$towards syn approach.

Keywords. Cyclohexane-1,2,3-triesters, $\alpha$-enolate-formation, methylation, protonation, solvent cavity.

\section{Historical background}

I have recently recounted ${ }^{1}$ how the Nobel Prize-winning Swiss organic chemist Leopold Ruzicka and his coworkers characterized a ' $\mathrm{C}_{11}$ acid' (tricarboxylic acid corresponding to the triester meso-1 1a) they had isolated from the oxidative degradation of the tricyclic diterpenic acid, abietic acid ${ }^{2}$, the main constituent of the violinists' 'rosin'. Elucidation of its configuration ${ }^{3}$ by another Nobel Prize-winning organic chemist, Derek Barton, led eventually to an understanding of the stereochemistry of alicyclic terpenic natural products, including steroids. These studies are of great historic importance in that they not only furthered the evolution of ideas of conformational

e-mail: snobchem@hotmail.com analysis but also led to formulation of the basics of biosynthesis of alicyclic natural products ${ }^{4}$ around the middle of the 20th century.
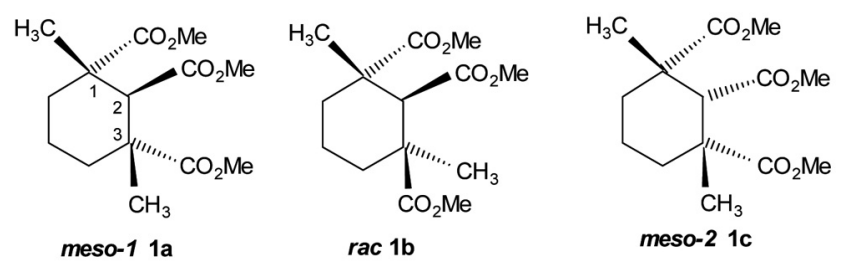

Not long after the study of oxidation products of abietic acid, Ruzicka and co-workers isolated from the oxidative degradation of another diterpene acid, agathic acid, a configurational isomer, viz. the ' $\mathrm{C}-11$ acid'. Isolated as a triester, it exhibited optical activity ${ }^{2}$ and was logically assigned the non-symmetric configuration $\mathbf{1 b}$, the racemic form of which I have labelled as rac $1 \mathrm{~b}$.

\section{Earlier work}

At a time when proof-by-synthesis still held sway in organic chemistry, an eventually successful attempt $\mathrm{t}^{5}$ was made to synthesize the $C_{11}$ acid, a heavily substituted 6membered ring with a pair of geminal methyl and carboxylic acid groups in 1,3-relationship. In a somewhat naïve approach, the unsaturated cyano-ester 2 (1-cyano-6alkoxycarbonyl-6-methylcyclohexene originally described by Linstead and Millidge $)^{6}$, was converted to a mixture with gross structure of the $C_{10}$ triester trimethyl 1-methylcyclohexane-1,2,3-tricarboxylate $\mathbf{4}$ following two routes via the nitrile esters $\mathbf{3 a}$ or $\mathbf{3 b}$ (Scheme 1).

For important reasons that cannot be treated here shortly but discussed in detail in ref. 5 , the formation of an $\alpha$-mono-enolate of triester 4 was expected to be regiospecific at C-3. However, the next step, methylation at $\mathrm{C}-3$, could be expected only to be stereoselective. While the product mixture 4 could consist of all four of the possible configurational isomers $\mathbf{4 a}-\mathbf{4 d}$, the methylation step product would yield only three isomeric products, viz. 1a-1c. It seemed worthwhile to carry through with the methylation and separation of the isomers. 


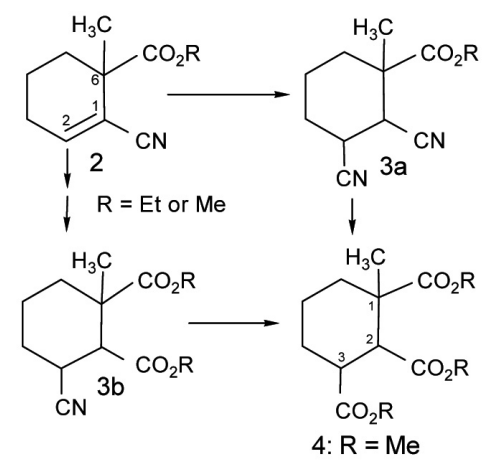

Scheme 1. Schematic of the sequence followed for the synthesis of gross structure of triester 4 .

Methylation was carried out following enolate formation employing triphenylmethyl sodium (tritylsodium). Elemental micro-analysis of the triester component of the product mixture showed it to consist only of the result mono-methylation. Attempts to isolate the individual methylated isomers from the mixture were not successful ${ }^{5}$.

The plan was changed to isolate, at the very outset, the configurationally isomeric $\mathrm{C}_{10}$ triesters $\mathbf{4 a}-\mathbf{4 c}$ and subject them to methylation individually, following characterization. In the initial attempts, only two of the four configurational isomeric possibilities could be isolated from the triester isomer mixture obtained at the end of the synthetic sequence. The first isomer gave a product that could be fully authenticated ${ }^{5}$ as meso- 1 1a (chemical name: methyl r-1-methyl-c-2,t-3-dimethoxycarbonyl-c-3methylcyclohexane-1-carboxylate), the trimethyl ester of the $\mathrm{C}_{11}$ acid having ester functions at $\mathrm{C}-1$ and $\mathrm{C}-2$ in trans relationship isolated from the oxidative degradation of abietic acid. The second isomer gave a trimethyl ester identified $^{5}$ as the racemic trimethyl ester rec $\mathbf{1 b}$ (chemical name: methyl r-1-methyl-c-2,c-3-dimethoxycarbonyl-t-3methyl-cyclohexane-1-carboxylate), having one pair of vicinal ester functions in cis relationship, the optically active form of which had been isolated by the oxidative degradation of another diterpene acid, agathic acid ${ }^{2}$.

These results made it clear that an $\alpha$-enolate was formed regiospecifically at C-3 in both cases (4a and $\mathbf{4 b}$ ) tried and that methylation was highly stereoselective even while demonstrating that the $\mathrm{C}-1$ and $\mathrm{C}-2$ ester groups were in trans-relationship (2a) in first triester and in cis-relationship in the second triester $(\mathbf{2 b})$, relationships that remain unaltered.

A third configurational isomer, labelled $\mathbf{4 c}$, was isolated and characterized using better controlled chromatographic analysis ${ }^{7}$ of the product mixture from the

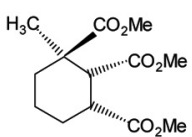

4a

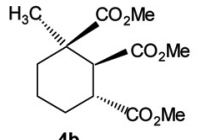

$4 b$

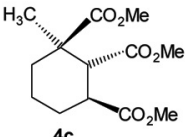

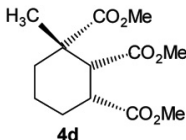

synthetic sequence of Scheme 1. ${ }^{1} \mathrm{H}$ NMR spectra recorded for carbon tetrachloride solutions of all three of triesters $\mathbf{4 a - 4 c}$ (as well as of the corresponding series of cyanoester precursors $\mathbf{3 a}$ and $\mathbf{3 b}$, the configurationally isomeric forms of which had been isolated and characterized) were strongly supportive of the assigned configurations $\mathbf{4 a - 4 c}$. The clearly resolved unsymmetrical doublets of the ' $A$ ' branches of the $\mathrm{ABX}_{n}$ spectra had small coupling constants $(J \approx 4-5 \mathrm{~Hz})$, generally indicating that the $\mathrm{C}-2$ and $\mathrm{C}-3$ protons were in synclinal relationship in the preferred conformations of the a-series, while the large coupling constants of the 'A' branch doublets $(J \approx 11.5-12 \mathrm{~Hz})$ were generally consistent with antiperiplanar relationship of the C-2 and C-3 protons in their preferred conformations in the $\mathbf{b}$ - and $\mathbf{c}$-series. The preferred conformations are set down as idealized representations $\mathbf{4} \mathbf{a}^{\prime}, \mathbf{4} \mathbf{b}^{\prime}$ and $\mathbf{4} \mathbf{c}^{\prime}$ ("cartoons ${ }^{8}$ of their chair forms). While these three triesters were formed in nearly equal proportions, no evidence could be gathered that the fourth, the all-cis ' $\mathrm{C}_{10}$ ' triester $\mathbf{4 d}$, had ever been formed.

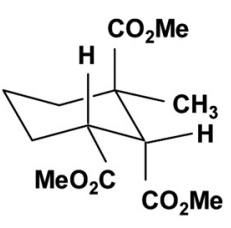

$4 a^{\prime}$

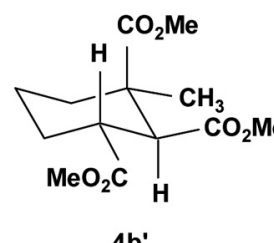

$4 b^{\prime}$

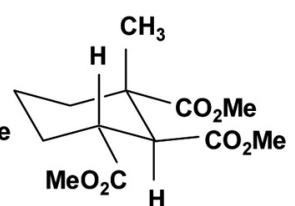

$4 c^{\prime}$
When once the preferred conformations were assigned, the results of enolate formation followed by methylation in the case of the triesters $\mathbf{4 a}$ and $\mathbf{4 b}$ were considered as having taken place by perpendicular approach of the methylating agent towards the exocyclic $\pi$-system of the cyclohexylidene C-3 enolates from the 'equatorial' side (Scheme 2).

\section{Unexpected aspects of behaviour of ' $C_{10}$ ' triesters 4a and $4 c$}

The configurational relationships among the substituent groups on the cyclohexane ring in the $\mathrm{C}_{10}$ triesters $4 \mathbf{a}$ and $\mathbf{4 c}$ would lead one to expect them to form a common C-3 anion on treatment with ethereal tritylsodium, the one from triester $4 \mathbf{c}$ also being expected to yield the $\mathrm{C}_{11}$ triester meso-1 1a on methylation. Remarkably, triester 1c was found not to form an enolate at all (no decolourization of the blood-red colour of tritylsodium). A possibility to consider was whether triester 1c would be formed when the C-3 enolate from triester $4 \mathbf{a}$ was quenched with water.

Ethereal tritylsodium was run in one lot in excess of one molar equivalent to a solution of triester $4 \mathbf{a}$ until the red colour of tritylsodium persisted for at least a few minutes. Vapour-phase chromatographic (VPC) analysis of samples drawn at arbitrary intervals (for experimental 
<smiles>CC1(O)CCC(O)CC1C=O</smiles>

Triester 4a'<smiles>CCOC(=O)C1CCCC(C)(O)C1O</smiles>

Triester $\mathbf{4} \mathbf{b}^{\prime}$

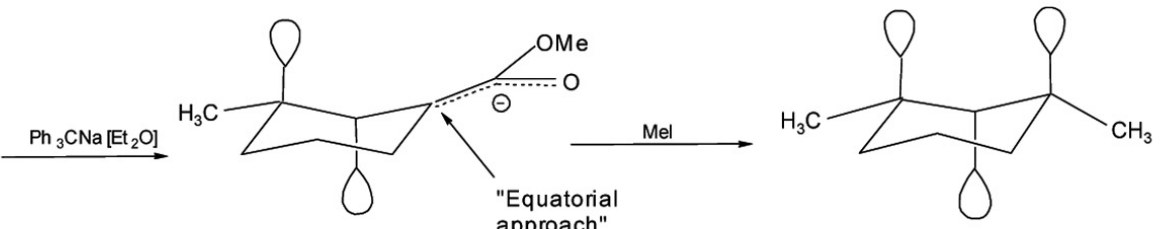

4a' C-3 enolate

meso1 1a (Methyl r-1-methyl-c-2,t-3-dimethoxycarbonylc-3-methylcyclohexane-1-carboxylate)

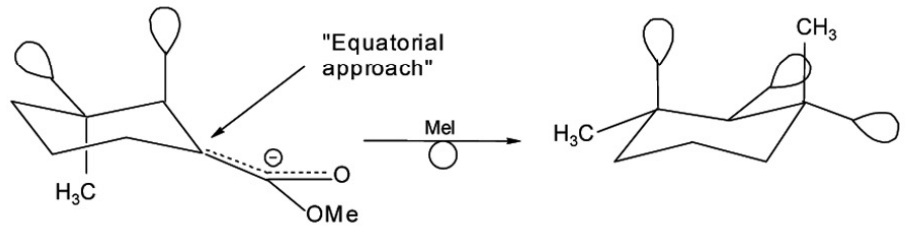

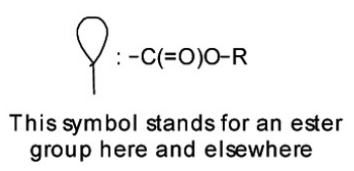

4b' C-3 enolate $\operatorname{rac} 1 \mathrm{~b}$ (Methyl r-1-methyl-c-2,c-3-dimethoxycarbonylt-3-methylcyclohexane-1-carboxylate)

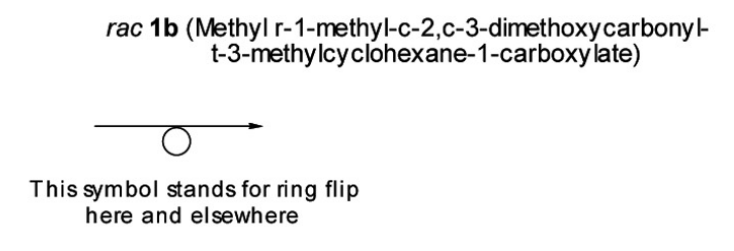

Scheme 2. Proposal for formation of C-3 methylated triesters meso $1 \mathbf{1}$ a and rac $\mathbf{1 b}$ (both represented in their likely preferred conformations) by perpendicular approach of the methylating agent towards the exocyclic $\pi$-system of the enolate from the 'equatorial' side of the cyclohexylidene C-3 enolates formed from triesters $\mathbf{4 a}$ and $\mathbf{4 b}$.
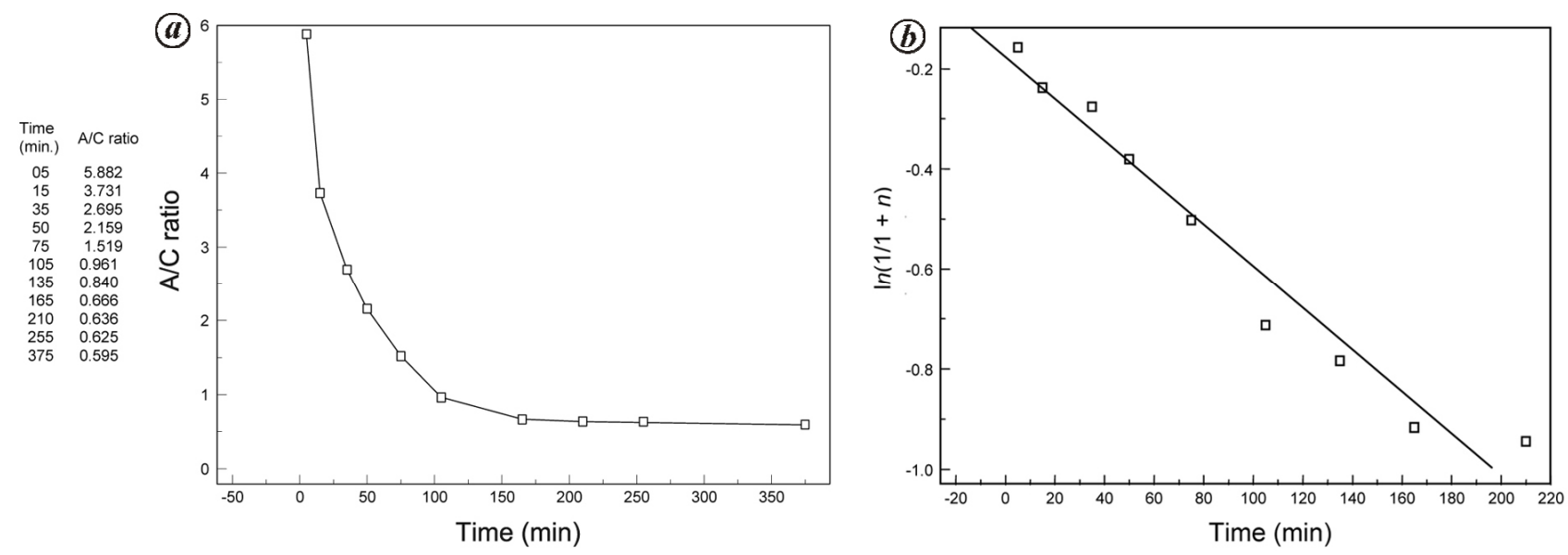

Figure 1. $\boldsymbol{a}$, Plot of progressive diminution with time of the ratio triester $\mathbf{4 a}$ /triester $\mathbf{4 c}$. Samples of the enolate prepared from triester $4 \mathbf{a}$ were drawn at intervals and quenched with water. The organic isolate was analysed by vapour-phase chromatography. $\boldsymbol{b}$, Logarthmic plot of the diminution of trimester $\mathbf{4 a}$ on conversion to the triester $\mathbf{4 c}$ against time (min.). Given: $10 \times \mathbf{4 c} / \mathbf{4 a} ;$ Actual $\mathbf{4 c} / \mathbf{4 a}=\mathrm{Given} / 10=n ; 1 / n=\mathbf{4 a} / \mathbf{4} \mathbf{c} ; \mathbf{4 c}=n \mathbf{4 a} ;$ Set $\mathbf{4 a}+\mathbf{4} \mathbf{c}=1 ; \mathbf{4 a}+n \mathbf{4} \mathbf{a}=1$ or $\mathbf{4 a}(1+n)=1 ; \ln \mathbf{4 a}=\ln (1 /(1+n))$ versus $t$. Parameters of the least-squares line: slope: $-4.18 \mathrm{E}-04$; Y-intercept: $-0.1760 \pm 0.03631$; Correlation coefficient: 0.9791 .

details see ref. 7) showed not only the appearance of the $\mathrm{C}_{10}$ triester $\mathbf{4 c}$ but also, surprisingly, a gradual decrease in the $4 \mathbf{a} / 4 \mathbf{c}$ ratio, the transformation taking about $8 \mathrm{~h}$ to reach a point beyond which VPC analysis could detect little or no change (Figure $1 a$ ).

Data on the change in the $4 \mathbf{a} / \mathbf{4} \mathbf{c}$ ratio with time had been reported in the 'Experimental' section of ref. 3, without further examination or processing. The plot of $\mathbf{2 a}$ in relation to $\mathbf{4 c}$ against time (Figure $1 a$ ), appeared quite smooth and clearly implied that the enolate $\mathbf{4}^{\prime} \mathbf{a}$ is formed in high concentration immediately after the addition of a calculated amount of tritylsodium in one lot. The mode of decrease of concentration of the enolate $\mathbf{2 a}^{\prime}$ appeared to follow unimolecular (first order) kinetics. Figure $1 b$ shows that the positions of the logarithms of points of diminution of $\mathbf{4 a}$ versus time as conversion to 4c proceeds fall in a line. The correlation coefficient of the least-squares straight plot (0.9791) can be taken as quite satisfactory given that the method of determining the $\mathbf{4 c / 4 a}$ ratios $^{3}$ was prone to a degree of uncertainty in 
the non-exacting conditions in which the experiment was conducted. Nevertheless, the result is considered as clearly indicating that the change is of the first order (please see later, relevant text).

The slow increase in the proportion of isomer $4 \mathbf{c}$ formed from $\mathbf{4 a}$ enolate, initially formed at high concentration, could not have been due to slow formation of the C-3 anion but could arise only from a wholly unexpected distinction between an 'a-type' anion and a 'c-type' anion. A correct interpretation of the diminution of the 4c/4a ratio with time (Figure 1) eluded us at the time the observations were made. The actual implication was that while methylation of the C-3 enolate of triester $4 \mathbf{a}$ involves approach of the methylating agent from the 'equatorial' side a proton needs to be deposited from the opposite 'axial' side if triester $\mathbf{4 a}$ were to be recovered at all on quenching its enolate with water. The curve demonsrates that this happens at each stage of the conversion at which the samples were drawn. The question now was whether the processes in the case of the c-type anion were similar to those in the a-type anion, protonation and methylation taking place in opposite ways.

\section{Is molecular anion-counterion aggregation a factor?}

It is well known from extensive studies starting from about the 1950s that enolate-counterion complexes tend to form molecular aggregates of high molecular weight that may precipitate out of non-polar and certain polar aprotic media ${ }^{9}$. The degree of polymerization (aggregation) may vary with solvent and structure and may be capable of impeding or altering the course of further reactions (references to these topics by well-known researchers in the field are too numerous to be listed here). The $\mathbf{4 a} \rightarrow \mathbf{4 c}$ transformation may have been retarded since it would have prima facie involved ion de-pairing and de-aggregation of the sodio-ester aggregate of an a-type before re-aggregating to form a second type of molecular aggregate of a c-type from which triester $4 \mathbf{c}$ would be generated on hydrolysis. A further question was whether molecular anion-counterion aggregation had any role to play in directing protonation versus methylation.

\section{Transformation of 4 a enolate to $4 c$ enolate requires the presence of $\mathrm{Na}^{+}$in excess}

The formation of an a-type molecular aggregate and its transformation to a c-type indicates that $\mathrm{Na}^{+}$needs to be present in excess, not only to allow transformation to take place but also to slow down its rate in a manner that would be inversely dependent on the amount of $\mathrm{Na}^{+}$ present in excess. For lack of adequate resources, such as for precise temperature control of apparatus and materials, no properly designed experiments for gathering kinetics data could be run to test the possibility which the original observations were made. However, an independent experiment, where the addition of tritylsodium was terminated after it had been added only in slight excess of the calculated amount showed that the transformation was meagre, if any, within the time allowed for the experiment $^{7}$. VPC analysis, after usual work-up, of a sample drawn after allowing the reaction mixture to stand for $3 \mathrm{~h}$ and quenching it with water showed that triester $\mathbf{4 c}$ could not be detected. We are now appreciative of the fact that in our original time-dependence experiment (Figure 1), $\mathrm{Na}^{+}$was accidentally present, within a range that permitted the $\mathbf{4 a} \rightarrow \mathbf{4 c}$ transformation to be slowed down sufficiently enough to be easily observed by conventional means.

\section{Further observations and attempted explanations}

Comparing the attributed preferred conformations $\mathbf{4} \mathbf{a}^{\prime}$ and $\mathbf{4} \mathbf{b}^{\prime}$ with $\mathbf{4} \mathbf{c}^{\prime}$, it appeared possible that the C-3 proton in triesters $\mathbf{4 a}$ and $\mathbf{4 b}$ was being activated (by the alkyl oxygen of the syn, axial ester function at $\mathrm{C}$-1) rendering it prone to facile removal, a situation that cannot arise in the case of triester $\mathbf{4 c}$ that has, instead, a syn, axial methyl group in its preferred conformation $\mathbf{4 c}^{\prime}$. Also, classic steric hindrance offered by the syn, axial methyl group at $\mathrm{C}-\mathrm{l}$ in triester $\mathbf{4} \mathbf{c}^{\prime}$ could prevent tritylsodium from approaching within a distance optimal for the abstraction of the proton at C-3.

\section{Studies with conformationally locked bicyclic systems}

The difference in the roles of a methoxycarbonyl and a methyl syn, axial to the C-3 proton was tested with bicyclic analogues that had no possibility of ring inversion $^{10}$. Methyl 9-methyl trans-decalin-2-carboxylate (5; Scheme 3), analogue of $\mathbf{4} \mathbf{c}^{\prime}$, did not form an $\alpha$-enolate as expected and as indicated by absence of discharge of the blood-red colour of the trityl anion. In significant contrast, methyl 9-ethoxycarbonyl-trans-decalin-2-carboxylate $\mathbf{6}$, analogue of $\mathbf{4} \mathbf{a}^{\prime}$ (or $\mathbf{4} \mathbf{b}^{\prime}$ ), readily formed an enolate, but the enolate resisted methylation under the conditions that had succeeded with both triesters $\mathbf{4 a}$ and $\mathbf{4 b}$.

Considering a possibility that the $\mathrm{C}-2 \alpha$-enolate, together with the C-9 ester function, forms a tight ion pair with the $\mathrm{Na}^{+}$counterion, the methylation experiment was done after adding the crown ether 15-crown-5 (Scheme 3) that has high selectivity for $\mathrm{Na}^{+}$but with no attendant success in methylation. However, the enolate did undergo reaction when hexamethyl phosphoric triamide (HMPTA; Scheme 3) was used as solvent for methylation with methyl iodide, but practically non-stereoselectively (antiC-9 ester/syn-C-9 ester $\approx 2 / 3$ as shown by ${ }^{1} \mathrm{H}$ NMR; 7). 

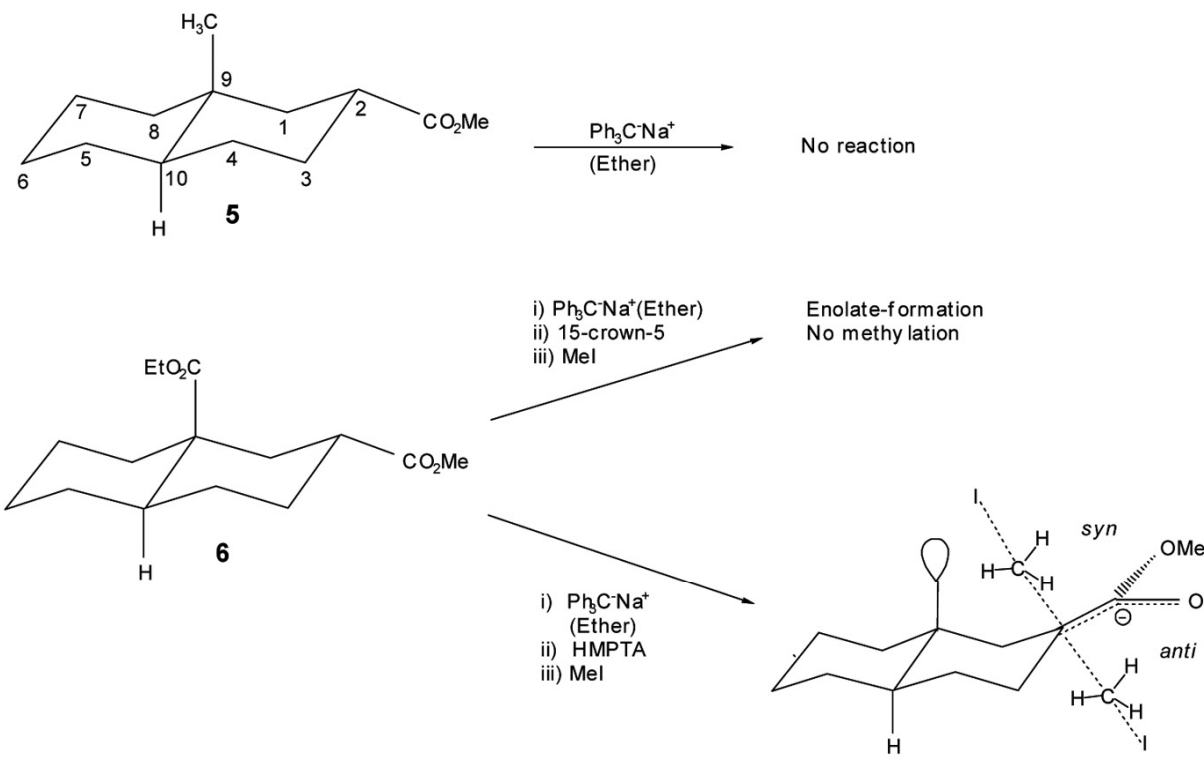

7: A 2/3 mixture ofyn and antiC-2 methylated products formed by the two approaches
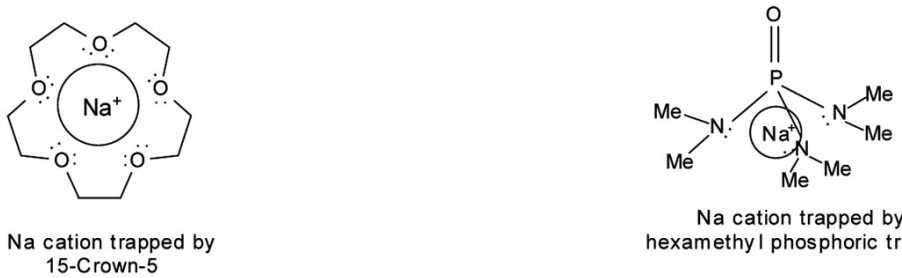

hexamethy I phos phoric triamide

Scheme 3. Methylation studies on methyl 9-methyl-trans-decalin- and methyl 9-ethoxycarbonyl-trans-decalin-2-carboxylates 5 and 6.

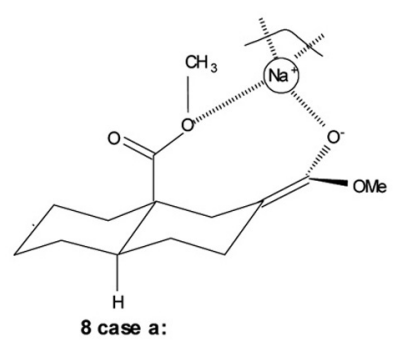

Unit of molecular aggregate both sym and anti methylation possible

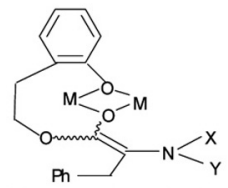

9: Instance of intramolecular
enolate-metal "aggregate"

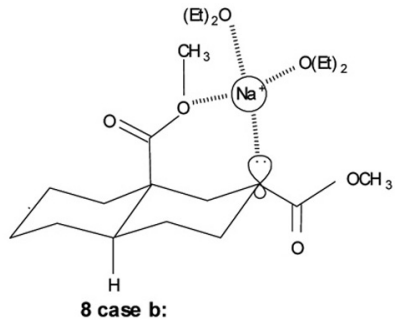

Conformational inflexibility stabilizes internal solvation No methylation

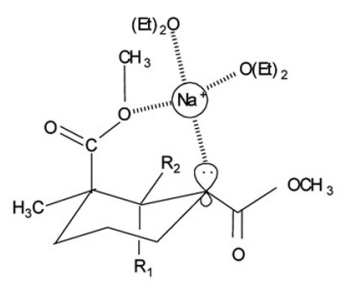

10: Unimolecular "aggregates" in the cases of monocyclic triester $\mathrm{C}-3$ enolates $4 a^{\prime}:\left(R_{1}=\mathrm{CO}_{2} \mathrm{Me} ; \mathrm{R}_{2}=\mathrm{H}\right)$ and
$4 \mathbf{b}^{\prime}:\left(\mathrm{R}_{1}=\mathrm{H}_{1} \mathrm{R}_{2}=\mathrm{CO}_{2} \mathrm{Me}\right)$

Scheme 4. Possible aggregated ( 8 case a) and unimolecular ( 8 case b) complexation in the case of trans-decalin diester $\mathbf{6}$. Structure $\mathbf{9}$ is engineered to form intramolecular complex involving two counterions ${ }^{11}$. Unimolecular 'aggregates' 10 formed from the triesters $4 \mathbf{a}^{\prime}$ and $4 b^{\prime}$ are analogous to 8 case $b$.

\section{Possibility of formation of molecular aggregates considered}

These results clearly implied that the syn, axial ester function at C-9 had a role in tightly binding the cation, so that a potent trapping reagent (HMPTA) was needed to 'expose' the carbanion. Two modes of complexformation (i) $\mathbf{8}$ case a and (ii) $\mathbf{8}$ case $\mathbf{b}$ (Scheme 4) can be envisaged for the decalin diester $6 \mathrm{C}-2$ enolate $-\mathrm{Na}^{+}$ cation paired system: in (i) based on the formation of polymeric molecular aggregates of enolate-counterion complexes $^{9}$ and (ii) based on the possibility that nonaggregated, soluble individual (or intramolecular) complexation of the enolate and counterion where, in the presence of a distinctive feature, a syn, axial-ester function, can play a role. In depicting $\mathbf{8}$ case $\mathbf{a}$, uniplanarity of the six-atom enolate system $\mathrm{C}-2-[\mathrm{C}-3-((\mathrm{C}=\mathrm{O})-$ $\mathrm{OMe})]^{-}-\mathrm{C}-4$, necessary for delocalization of the negative charge, is taken as maintained. The $\mathbf{8}$ case a unit structure is assumed as being repeated many times over in the polymeric molecular aggregation. Even while the facility of reactions of the enolate species, such as methylation, may not be seriously affected, it appeared unlikely that the $\mathrm{Na}^{+}$cation would be able to exert any influence on the 


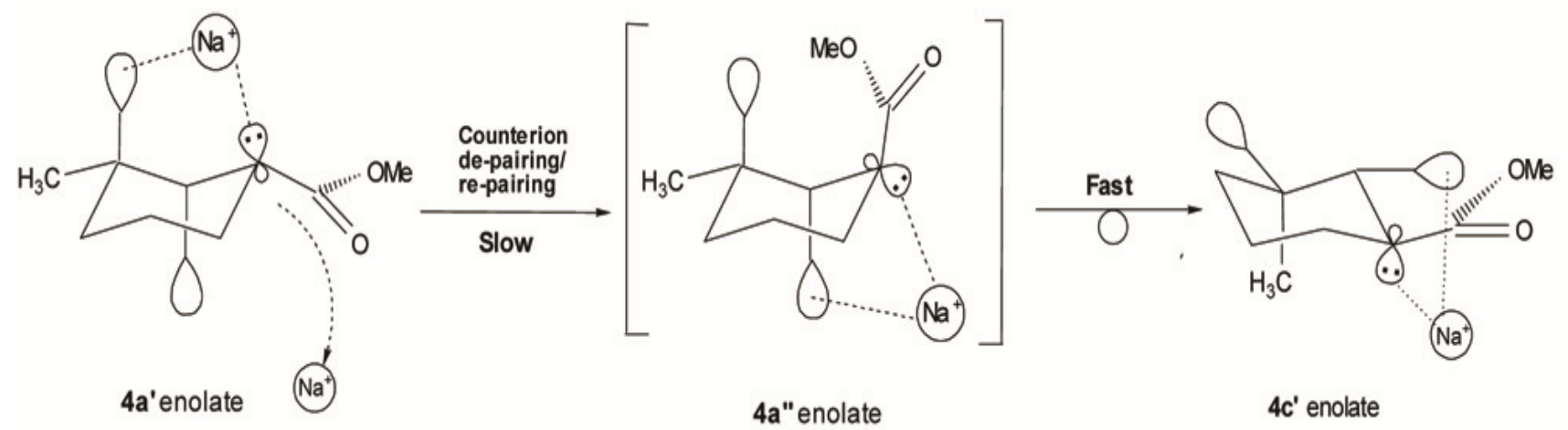

Scheme 5. Possibility that $\mathbf{4} \mathbf{a}^{\prime}$ enolate gets converted to $\mathbf{4} \mathbf{a}^{\prime \prime}$ enolate through a slow (rate-determining) process of counterion de-pairing - re-pairing events considered. The presence of tritylsodium in excess in order to ensure availability of 'free' $\mathrm{Na}^{+}$may be necessary. The $\mathbf{4} \mathbf{a}^{\prime \prime}$ enolate can undergo instantaneous ring flip to the $\mathbf{4} \mathbf{c}^{\prime}$ enolate, likely the favoured form. Molecules of diethyl ether (the solvent) that

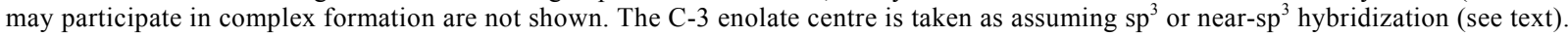

stereochemical outcome of methylation because of its unfavourable positioning in relation to the enolate species.

The intramolecular case 8 case $\mathbf{b}$ that offers a contrast may be considered as more relevant to the situation presented by the decalin diester $\mathbf{6}$, where the syn, axial C-9 ester function is well-positioned to participate, likely via its alkyl oxygen, in forming an individual (nonaggregating) intramolecular complex in conjunction with the enolate centre. There is an instance where a precursor was engineered to cause the derived $\mathrm{K}^{+}$-enolate to form only an intramolecular 'aggregate' 9 (ref. 11). Involving two counterions, complex 9, with an enolate and a phenoxide (Scheme 4) differs from the simpler 8 case $\mathbf{b}$, where the structural features are conducive to trap a single counterion.

Of much pertinence here is the possibility that the $\mathrm{C}-2$ $[\mathrm{C}-3-((\mathrm{C}=\mathrm{O})-\mathrm{OMe})]^{-}-\mathrm{C}-4$ six-atom system departs from proper uniplanarity, in the manner that $\mathrm{Cram}^{12}$ has discussed for those cases where ion-pairing can cause these effects. Such a possibility allows one to believe that the negative charge moves more towards a trigonal pyamidally hybridized carbon $\mathrm{C}-3$ as the intramolecular $\mathrm{Na}^{+}$ complex is formed.

The geometric parameters of the decalin diester 5 internal complex 8 case $\mathbf{b}$ appear to resemble closely the mode by which 5-crown-15 traps $\mathrm{Na}^{+}$(Scheme 3 ). Such a resemblance appears to be the likely reason for the inability of added 5-crown-15 to remove $\mathrm{Na}^{+}$from the internal complex 8 case $\mathbf{b}$. The presence of an ester function syn, axial in the triesters $\mathbf{4} \mathbf{a}^{\prime}$ and $\mathbf{4} \mathbf{b}^{\prime}$ in a situation (10) resembling $\mathbf{8}$ case $\mathbf{b}$ may lead to the expectation that strong internal trapping of $\mathrm{Na}^{+}$could hold good in these two cases also. However, conformational flexibility, aided by thermal agitation, possible in the monocyclic systems $\mathbf{4} \mathbf{a}^{\prime}$ and $\mathbf{4} \mathbf{b}^{\prime}$, may destabilize them to make a difference that renders methylation (with methyl iodide) possible in their cases.

\section{Mechanism for slowing down $4 a^{\prime}$ enolate $\rightarrow 4 c^{\prime}$ enolate conversion}

The complex $\mathbf{1 0}$ relating to the conformationally flexible case $\mathbf{4} \mathbf{a}^{\prime}$ may stay solubilized as a comparatively weakened individual complex (a-type). Mechanisms can be considered now for its conversion to a second form (ctype) that yields triester $\mathbf{4 c}$ on protonation. Why that conversion is so slowed down that it can be followed using conventional means needed to be answered. As depicted in Scheme 5, the event of counterion de-pairing followed by one of re-pairing when tritylsodium is present in excess, forming a new complex, could well be the rate-determining step. Designated as $\mathbf{4} \mathbf{a}^{\prime \prime}$, the new enolate complex involves the C-2 ester function. A mere ring flip can then transform this complex into the C-3 enolate of triester $\mathbf{4} \mathbf{c}^{\prime}$ that is not accessible by direct deprotonation of triester $\mathbf{4 c}$ with tritylsodium.

\section{Methylation and protonation from opposite faces of the complexes}

A difference can now be seen in the mechanisms of methylation and protonation. The $\mathbf{4 a}^{\prime}$ enolate- $\mathrm{Na}^{+}$complex yields the $\mathrm{C}_{11}$ triester meso-1 1a when methylated within a short time after its formation. If the complex was structured as shown, the approach of the methylating agent must be towards the face not containing the $\mathrm{Na}^{+}$cation since that face is not sterically hindered. On the other hand, the time-dependence experiment has shown that quenching samples, drawn at arbitrary intervals, with water regenerates the triester $\mathbf{4 a}$ by protonating the remnant part of the $\mathbf{4 a}^{\prime}$ enolate that has yet to transform into the $\mathbf{4} \mathbf{c}^{\prime}$ enolate. This implies that protonation must take place from the same face as the one $\mathrm{Na}^{+}$occupies (Scheme 6a).

CURRENT SCIENCE, VOL. 116, NO. 12, 25 JUNE 2019 


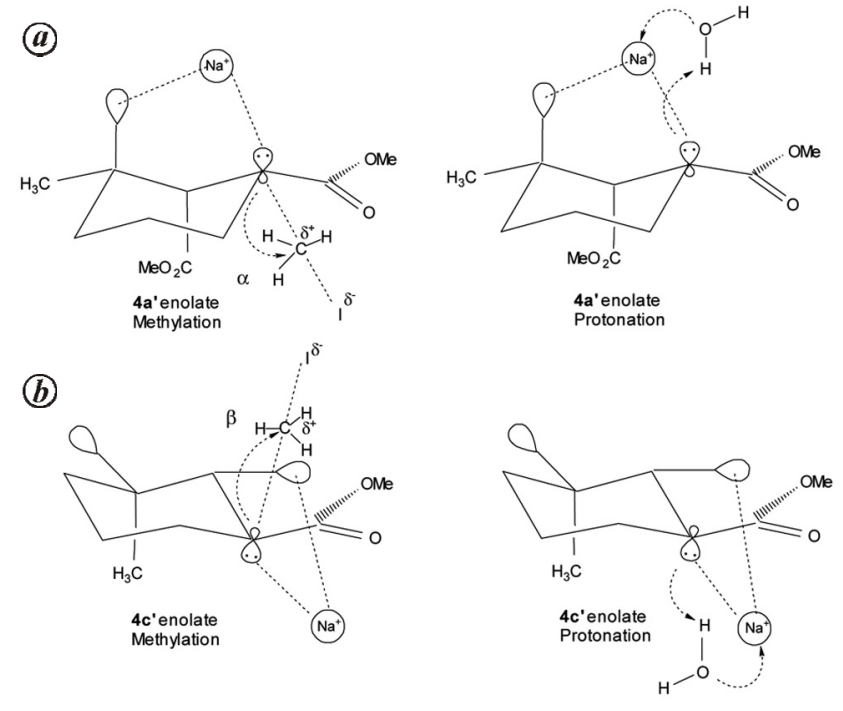

Scheme 6. The opposed modes of methylation and protonation, and accompanying change in mechanism for both $\mathbf{4 a}^{\prime}$ and $\mathbf{4} \mathbf{c}^{\prime}$ enolates. While methylation is from the same side where the approach is less sterically hindered, the one for hydrolysis of the enolate complex is guided by $\mathrm{Na}^{+}$ion.

\section{A relevant instance}

An interesting difference in stereochemical outcomes of methylation when employing the non-complex-forming agent methyl iodide and an initial complex-forming agent trimethyl phosphate as the methylating agents is given by Chaissaing et al. ${ }^{13}$, partly indicated in Scheme 7, of the methylation of C-2 lithio-enolates of cis and trans 4-tertbutylthiane S-oxides, where the equatorial tert-butyl group anchors the conformations shown. The differences were attributed to the mode of action between methyl iodide and trimethyl phosphate, possibly in the manner shown for one case in the methylating process included in Scheme 7.

An attempt was made to methylate triester $4 a^{\prime}$ C-3 enolate replacing methyl iodide with trimethyl phosphate as the methylation agent. In a short-interval experiment, the enolate was quenched with trimethyl phosphate within 15 min of its formation. The product was found by VPC analysis to contain, besides the starting triester $\mathbf{4 a}$, the triester $4 \mathbf{c}$ and the C-3 methylated product of configuration $\mathrm{rac} \mathbf{1 b}$ in the ratio $5: 5: 2$ (for experimental data and initial interpretation see ref. 10). Recovery of much of the triester 4a demonstrated that methylation with trimethyl phosphate is sluggish, slower than with methyl iodide. The slower rate of methylation allows an opportunity for the $\mathbf{4} \mathbf{a}^{\prime}$ enolate to transform into the $\mathbf{4 c}^{\prime}$ enolate the methylation of which, in any case, is likely to be slow in view of the syn, axial hindrance offered by the C-1 methyl group. An important indication was that the methylated product rac $\mathbf{1 b}$ could have arisen exclusively from the $\mathbf{4} \mathbf{a}^{\prime}$ enolate because methylation by trimethyl phos- phate takes place on the same face of the cyclohexane ring as that occupied by $\mathrm{Na}^{+}$.

\section{Behaviour of $4 c^{\prime}$ enolate strongly supports the processes envisaged}

The behaviour of the $\mathbf{4} \mathbf{c}^{\prime}$ enolate produced by the isomerization of the $\mathbf{4} \mathbf{a}^{\prime}$ enolate paralleled that of its parent enolate in all noteworthy features, strongly supporting the envisaged modes. If the attempt to methylate the $\mathbf{4} \mathbf{a}^{\prime}$ enolate is delayed by a few hours the product of methylation turns out to be an 8:1 mixture of the $\mathrm{C}_{10}$ triester $\mathbf{4 c}$ and the $\mathrm{C}_{11}$ triester of configuration rac $\mathbf{1 b}$, no trace of formation of the $\mathrm{C}_{11}$ triester of configuration meso-1 1a being found $^{10}$. This could mean that methylation of the $\mathbf{4} \mathbf{c}^{\prime}$ enolate, formed via transformation of the $\mathbf{4} \mathbf{a}^{\prime}$ enolate, is much slower than the methylation of the $\mathbf{4} \mathbf{a}^{\prime}$ enolate. Of much greater significance, however, is that the $\mathbf{4} \mathbf{c}^{\prime}$ enolate must get methylated from the face not occupied by $\mathrm{Na}^{+}$in order that the $\mathrm{C}_{11}$ triester rac $\mathbf{1 b}$ be formed. In connection with the observations made in the timedependence experiment, one sees that protonation (hydrolysis) must have taken place from the same side as that occupied by $\mathrm{Na}^{+}$for the regeneration of triester $4 \mathbf{c}$ from the $\mathbf{4} \mathbf{c}^{\prime}$ enolate (Scheme 6 ) ).

Scheme 8 comprehensively presents the phenomena described thus far.

\section{Support for envisaged processes from the behaviour of $\mathrm{C}_{10}$ triester $4 \mathrm{~b}$}

The behaviour of the $\mathrm{C}_{10}$ triester $\mathbf{4 b}$ was entirely consonant with what has been reconstructed from the experimental evidence logically interpreted as showing that protonation and methylation of the $\mathrm{C}-3$ enolate derived from the $\mathrm{C}_{10}$ triester $\mathbf{4 a}$ and, in turn, that from the $\mathrm{C}_{10}$ triester $\mathbf{4 c}$ take place on opposed faces and two different mechanisms. Two experiments were conducted with triester $\mathbf{4 b}$, one allowing only a short interval $(<5 \mathrm{~min})$ and another allowing a long interval $(\sim 2 \mathrm{~h})$ between enolate formation and methylation ${ }^{14}$.

It is noteworthy that, in contrast with the $\mathrm{C}_{10}$ triester 4a, 1,3-allylic strain $\left(\mathrm{A}^{(1,3)} \text { strain }\right)^{15}$ involving the ester function at $\mathrm{C}-2$ will be generated in the $\mathrm{C}_{10}$ triester $4 \mathrm{~b}$ on enolization of the ester function at $\mathrm{C}-3$, when the sixatom enolate system $\mathrm{C}-2-[\mathrm{C}-3-(\mathrm{C}=\mathrm{O})-\mathrm{OMe})]^{-}-\mathrm{C}-4$ is rendered planar. The carbonyl carbon of the $\mathrm{C}-2$ ester function and an oxygen atom (either carbonyl or alkyl) of the C-3 enolized ester function would be brought within a distance similar to that between two adjacent atoms in a flat five-membered ring (see uppermost left diagram in Scheme 9). Allylic strain can be mitigated when the enolate system departs from uniplanarity and hybridization at $\mathrm{C}-3$ moves towards $\mathrm{sp}^{3}$, the $\mathrm{C}-3$ centre thus carrying 


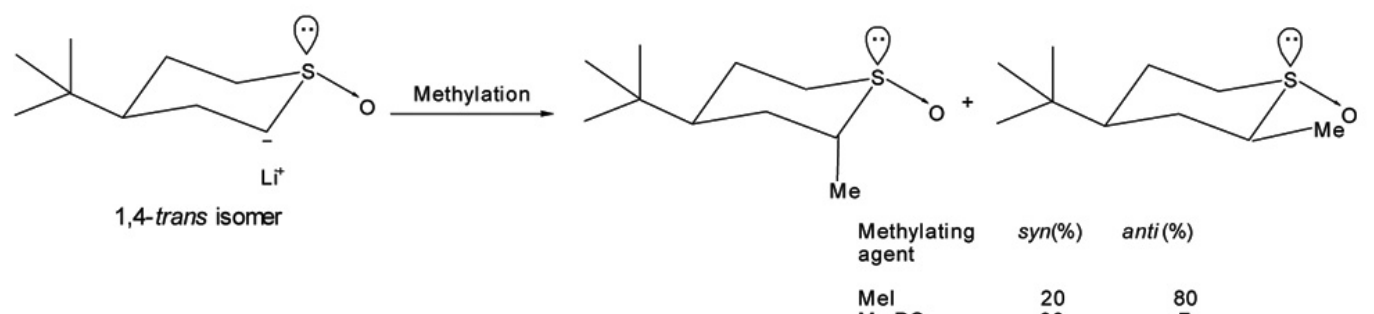<smiles>CC(C)(C)C1CCS(O)(O)CC1</smiles>

Methylation

$\mathrm{Li}^{+}$

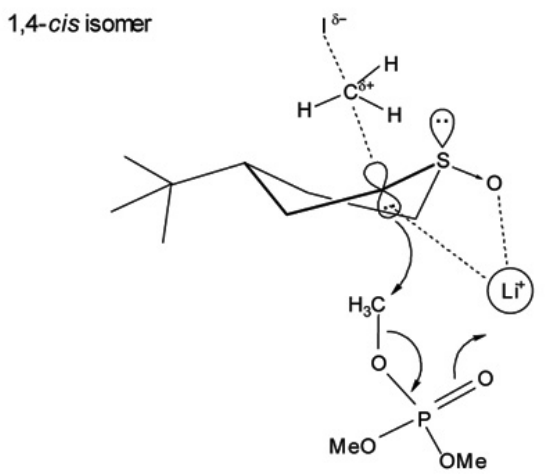<smiles>CC1CC(C(C)(C)C)CCS([O])([O-])C1</smiles><smiles>CC1CCC(C(C)(C)C)CCS1(=O)=O</smiles>

Methylating syn (\%) anti (\%)

$\begin{array}{lcc}\mathrm{Mel} & 100 & 0 \\ \mathrm{Me}_{3} \mathrm{PO}_{4} & 30 & 70^{0}\end{array}$

syn and antirefer to

the sulphoxide oxygen

Scheme 7. Methyl iodide and trimethyl phosphate behave differently, as shown for the cis case, in methylating the C-2 lithio-enolates of each of the cases of trans and cis 4-tert-butylthiane S-oxides. The modes syn and anti are with reference to the $\mathrm{S} \rightarrow \mathrm{O}$ group.
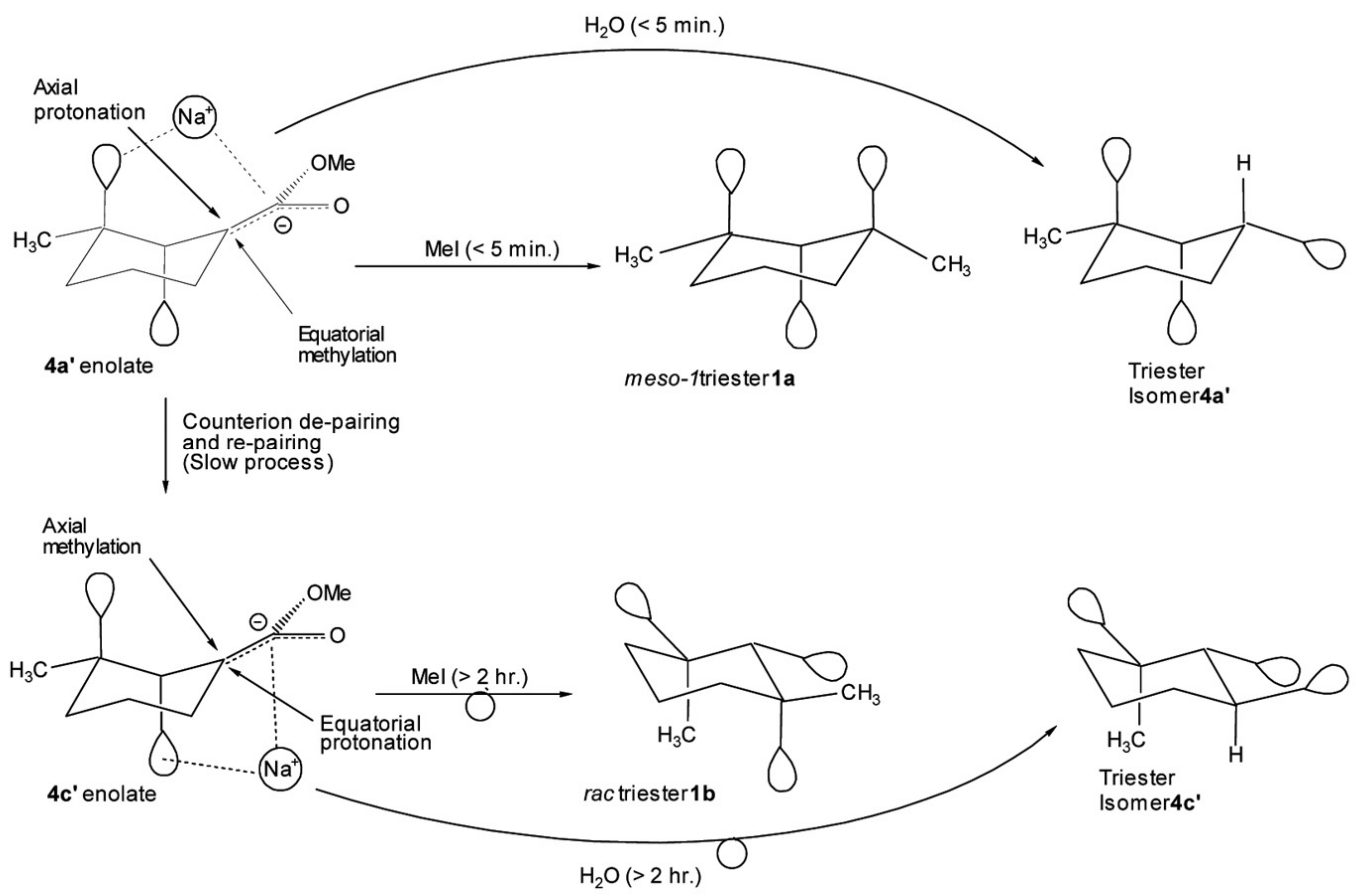

Scheme 8. Behaviour of the enolate derived from triester 4a. Short-interval experiments: protonation is 'axial' and regenerates triester $\mathbf{4 a}$; methylation is 'equatorial' giving rise to triester meso-1 1a. Long-interval experiments: $\mathbf{4} \mathbf{c}^{\prime}$ enolate has sufficient time to be formed. Protonation, guided by $\mathrm{Na}^{+}$, is 'equatorial' giving rise to triester isomer 4c. Methylation, now 'axial', leads to the formation of triester rac $\mathbf{1 b}$. 


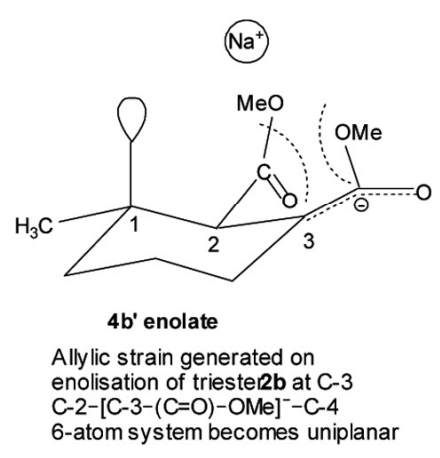

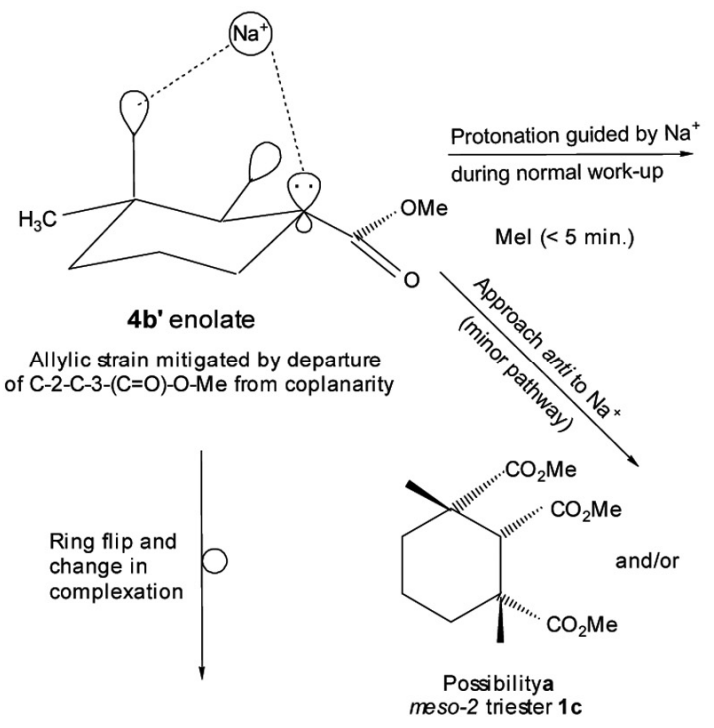
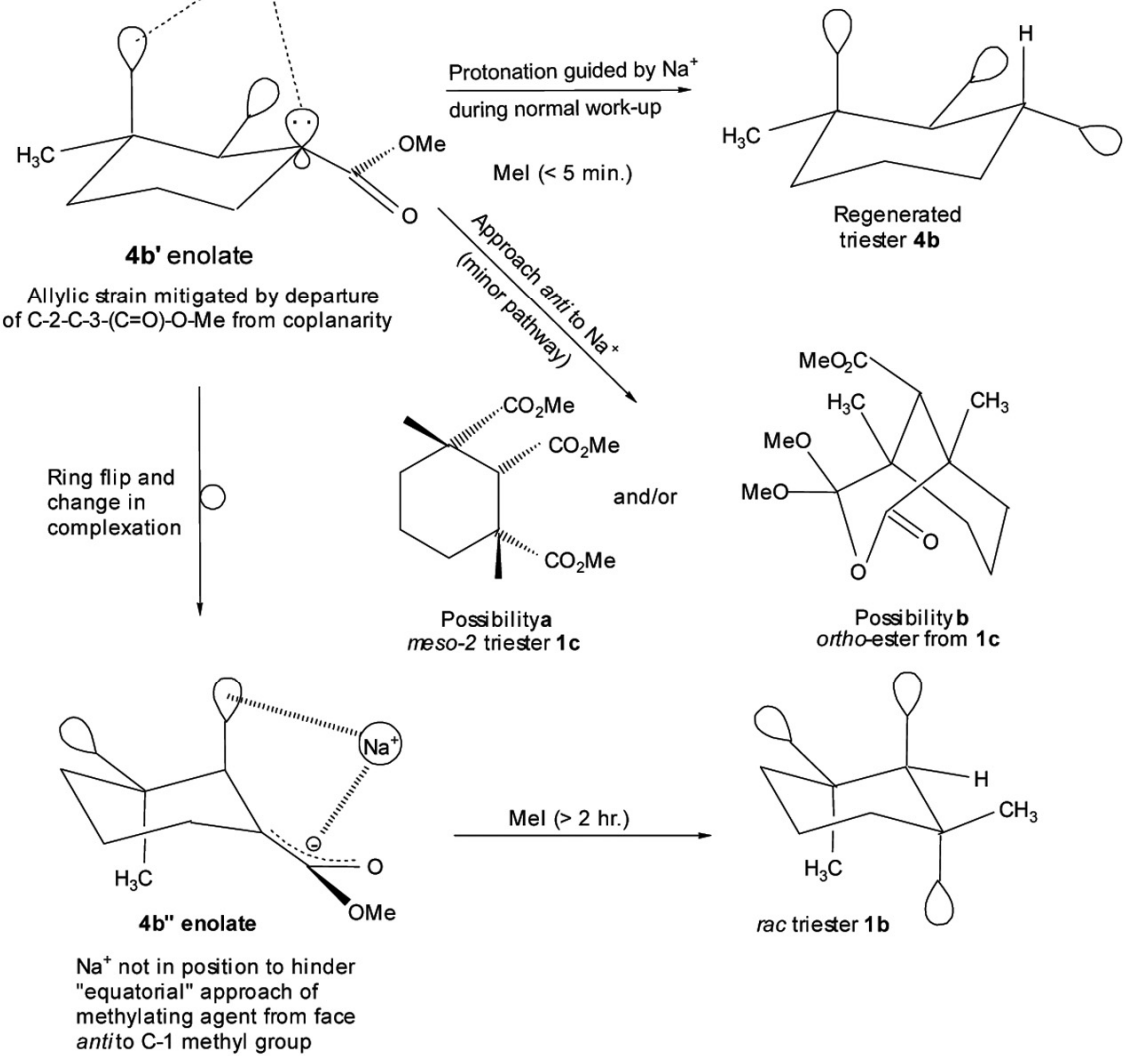

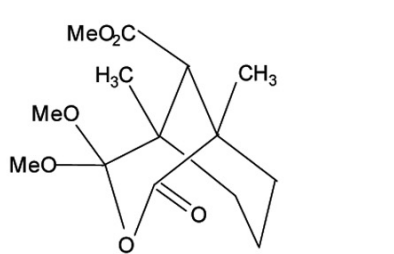

Possibility b
ortho-ester from 1c

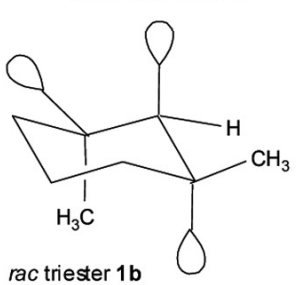

rac triester $\mathbf{1 b}$

Scheme 9. Transformations and reactions of $\mathbf{4} \mathbf{b}$ ' enolate derived from the $\mathrm{C}_{10}$ triester $\mathbf{4 b}$ after allowing 'short' and 'long' intervals before methylation post formation.

greater negative charge. This latter factor can act in addition to the participation of $\mathrm{C}-3$ in complex formation (Scheme 9; $\mathbf{4} \mathbf{b}^{\prime}$ enolate) in a manner discussed earlier for the case of system $\mathbf{4 a}^{\prime}$. Another way the allylic strain can be mitigated is for the cyclohexane ring to invert into the form shown as $\mathbf{4} \mathbf{b}^{\prime \prime}$ enolate in Scheme 9. This process would be slowed down since it involves the decomplexation and re-complexation of $\mathrm{Na}$ cation.

The results of methylation experiments carried out with triester $\mathbf{4 b}$ were generally in support of the processes just described. Most of triester 4b was recovered, apparently unchanged, in the short-interval methylation experiment, but actually because it must have been reformed during work-up by protonation guided by the $\mathrm{Na}^{+}$cation from the same face that it occupies (structure $\mathbf{4} \mathbf{b}^{\prime}$ ). Interestingly, a small amount of a material found among the products of methylation exhibited a ${ }^{1} \mathrm{H}$ NMR spectrum compatible with either or a mixture of two structures, the methylated $\mathrm{C}_{11}$ triester of meso-2 configuration 1c (Possibility a Scheme 9; technical name: methyl r-1-methylc-2,t-3-dimethoxycarbonylcyclohexane-1-carboxylate) and its derived ortho-ester (Possibility b Scheme 9). This was not examined further. The rac triester $\mathbf{1 b}$ was formed in good yield in the long-interval experiment, the methylat- ing agent having approached the ring from the less hindered 'equatorial' side. As implied in the $\mathbf{4} \mathbf{b}^{\prime \prime}$ enolate complex, the C-1 axial methyl hinders axial approach while the $\mathrm{Na}$ cation is not in a position to hinder equatorial approach. This clearly demonstrates that the initial complex $\mathbf{4} \mathbf{b}^{\prime}$ has undergone transformation to the enolate $4 b^{\prime \prime}$.

\section{Why $4 a^{\prime}$ enolate is formed at high initial concentration}

A search disclosed two instances pertinent to this study retention of configuration in the manner envisaged during the formation of enolates from triesters $\mathbf{4 a}$ and $\mathbf{4 b}$. An early one involved the replacement of a halogen in an optically active (asymmetric) iodohydrocarbon by lithium $^{16}$. The formation of 2-methyloctanoic acid in enantiomeric excess found at the end of the sequence shown in Scheme 10 could be the result, as stated by the author $^{16}$, of either predominant maintenance of retention or predominant inversion for both the halogen-metal interchange and carbonation reactions.

If the processes shown in Scheme 5 were to account for the slowing down of isomerization of enolate $\mathbf{4 a}^{\prime}$ to 
enolate $\mathbf{4} \mathbf{c}^{\prime}$, inversion at the step of replacement of the C-3 proton by $\mathrm{Na}^{+}$cannot be involved. Cram ${ }^{12}$ invoked the idea of formation of a 'solvent cage' in cases where a deuteron replaces a proton under base-catalysed conditions with retention, even though the transition state were to change from trigonal pyramidal $\mathrm{sp}^{3}$ to a flat $\mathrm{sp}^{2}$ hybridized species ${ }^{17}$.

However, resemblance of the process that effectively causes replacement of the C-3 proton by coordinated $\mathrm{Na}^{+}$ with $\mathrm{H}-\mathrm{D}$ exchange with retention cannot be carried too far since the proton-abstracting agent $\mathrm{Ph}_{3} \mathrm{C}^{-}$appears to be too large to be accommodated, together with the sodium ion, within the reaction domain ('cage' or 'cavity') on the 'upper' face of the cyclohexane triester. Conducted in an aprotic but polar solvent (diethyl ether), the reaction seems only too likely to consist of two separate steps: clean removal of the proton to be followed by coordination of sodium ion, whereby an interval must lapse between the two events giving the $\mathbf{4} \mathbf{a}^{\prime}$ enolate (as well as the $\mathbf{4} \mathbf{b}^{\prime}$ enolate) an opportunity to undergo fast conformational change (ring inversion with $\mathrm{sp}^{3}$ rehybridization). Even though involving just ring flip (or pseudorotation), that change does not seem to happen fast even at room temperature. One may think that the enolate ion preserves, seemingly, its trigonal pyramidal hybridization within the required timescale of replacement of the C-3 proton by $\mathrm{Na}^{+}$.

\section{Possible role of solvent in the retention of configuration}

The second instance is from a study of a phenomenon called 'memory effect' ${ }^{18}$. This term has been applied, in a generalized way, to a system where, as considered in ref. 18 , 'formal substitution at an $\mathrm{sp}^{3}$ stereogenic centre that proceeds stereospecifically, even though the reaction proceeds by trigonalization of that centre, and despite the fact that no other permanently chiral elements are present in the system'.

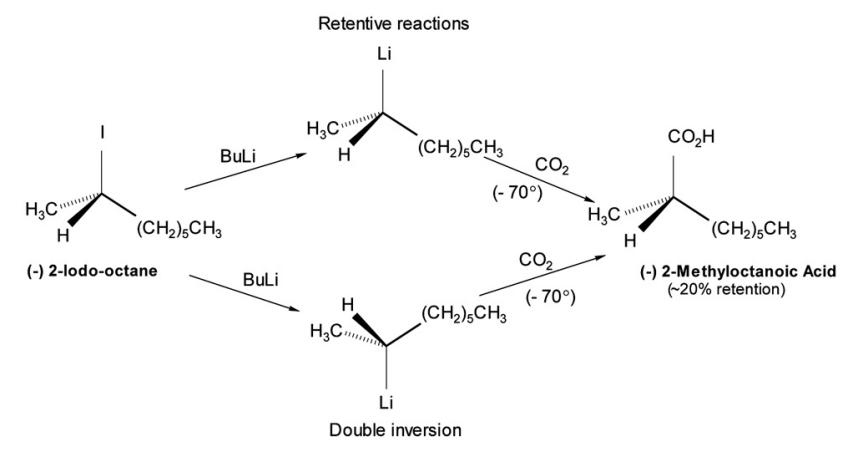

Scheme 10. Transformation of (-) 2-iodöoctane to (-) 2-methyloctanoic acid via lithiation followed by carbonation.
Kawabata et al. ${ }^{19}$ found that enantiomeric excess (ee) decays with the interval allowed before methylation (Scheme 11). Deprotonation of optically active amino acid derivative A with potassium hexamethyldisilazide followed by addition of methyl iodide, carried out at $-78^{\circ} \mathrm{C}$, generates methylated product $\mathbf{B}$ with high $e e$ indicating the cation retains tetrahedral (central) asymmetry. The ee diminishes on allowing longer lapses of time before methylation, indicating that even at low temperature $\left(-78^{\circ} \mathrm{C}\right)$ the anion $\mathbf{C}$ becomes planar $\left(\mathrm{sp}^{2}\right)$ hybridized to the flat system $\mathbf{D}$. The phenomenon of retention of asymmetric distribution around the central carbon even for a short time was attributed to the 'memory effect'.

This, in an overall sense, is similar to how we have now interpreted our earlier observation of the $\mathbf{4 A}^{\prime}$ enolate to $\mathbf{4} \mathbf{C}^{\prime}$ enolate transformation except that it is easily measurable at room temperature $\left(\sim 25^{\circ} \mathrm{C}\right)$, whereas Kawabata et al. ${ }^{19}$ studied the change at $-78^{\circ} \mathrm{C}$. The possible role of the solvent - formation of a chirality-preserving solvent cage - appears not to have been considered, to the best of the author's knowledge, specifically to account for the memory effect in terms of resistance of the solvent cage to reshape itself quickly to accommodate the change in geometry of the subject molecule when a centre of chirality undergoes change in hybridization.

The generalized statement on the memory effect mentioned above is not strictly applicable to the cases of the triesters $\mathbf{4 a}$ and $\mathbf{4 b}$ considered by us in so far as both have present in them permanently chiral centres, C-1 and C-2. Nevertheless, we have noted that the C-3 enolate centre behaves in a comparable manner in retaining the configuration since, during the interval between proton removal by $\mathrm{Ph}_{3} \mathrm{C}^{-}$and its replacement by $\mathrm{Na}^{+}, \mathrm{C}-3$ has a chance to become trigonal (changing to $\mathrm{sp}^{2}$ hybridization) and $\mathrm{Na}^{+}$ can complex, in theory, from either side. However, with
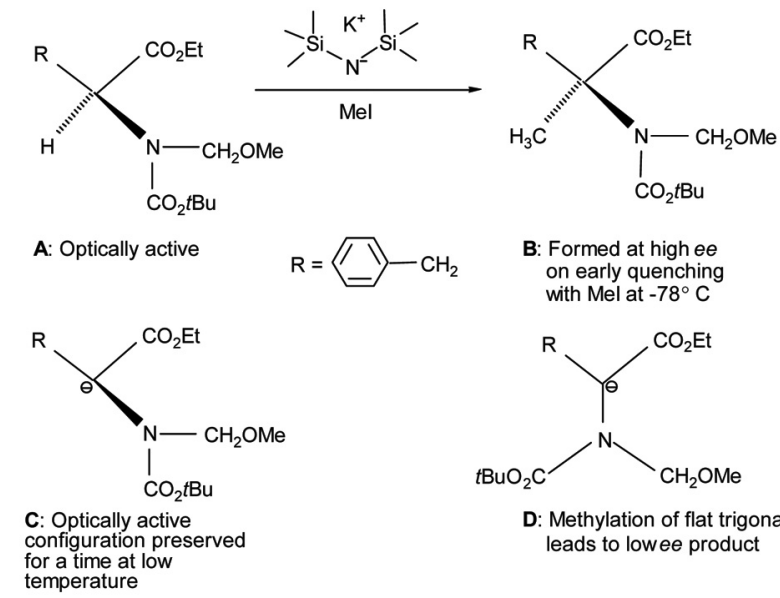

B: Formed at high ee on early quenching
with Mel at $-78^{\circ} \mathrm{C}$

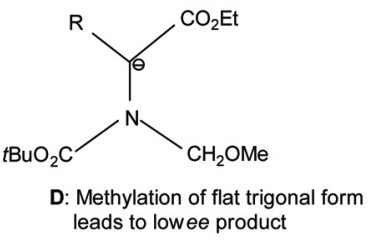

Scheme 11. Methylation of an anion $\mathbf{C}$ derived from the $\alpha$-amino acid derivative A gives the optically active methylated derivative $\mathbf{B}$ with high enantioselectivity at low temperature. The selectivity decreases with time allowed before methylation. 
any change in the initial geometry that may accompany the removal of the $\mathrm{C}-3$ proton, the change in hybridization at C-3 would be resisted by the simultaneous need to change the shape of the cavity of the solvent cage, especially when polar ester functions are present on the cyclohexane ring. The delay (or hysteresis), an effect resembling the memory effect, allows time for the $\mathrm{Na}^{+}$ cation to form complexes in the cases of both $\mathbf{4 a}^{\prime}$ and $\mathbf{4} \mathbf{b}^{\prime}$ enolates in a manner that appears to make C-3 maintain its trigonal pyramidal $\mathrm{sp}^{3}$ hybridization. This position explains why these complexes are formed in high initial concentration.

\section{Conclusion}

The aim of the present study was to arrive at a selfconsistent interpretation of all phenomena encountered in the diverse behaviours, described in earlier publications, of three $(\mathbf{4 a}, \mathbf{4 b}$ and $\mathbf{4 c})$ of the four possible configurationally different isomers of trimethyl 1-methylcyclohexne-1,2,3-tricarboxylate. While triesters $\mathbf{4 a}$ and $\mathbf{4 b}$ can be deprotonated regiospecifically at $\mathrm{C}-3$ and the generated enolates can be methylated to yield triesters of tricarboxylic acids known to be degradation products of abietic and agathic acids respectively, the third isomer 2c cannot be deprotonated under the conditions that are effective in the first two cases. ${ }^{1} \mathrm{H}$ NMR-based assignment of conformations revealed the reasons for this difference in behaviour. The $\mathbf{4} \mathbf{a}^{\prime}$ enolate was expected to transform instantly into an enolate that would yield isomer $\mathbf{4 c}$ on reprotonation, but it underwent transformation at a surprisingly slow rate. The enolates and associated $\mathrm{Na}^{+}$ counterions appear not to form molecular complexes but stay as individual, intramolecularly complexed entities, very likely involving the polar aprotic solvent, diethyl ether. A rate-determining process of de-complexation-recomplexation intervenes and slows down the transformation of the $\mathbf{4} \mathbf{a}^{\prime}$ enolate to the $\mathbf{4} \mathbf{c}^{\prime}$ enolate. The formation of a solvent-cavity around the enolate- $\mathrm{Na}^{+}$complex and its resistance to change in shape are considered as reasons to slow down transformation of the trapped entity. Protonation and methylation take place on opposite faces of the cyclohexane ring by different mechanisms in both cases of the C-3 enolates derived from triesters $\mathbf{4 a}$ and $\mathbf{4 b}$. The Reason why $\mathbf{4} \mathbf{a}^{\prime}$ and $\mathbf{4} \mathbf{b}^{\prime}$ enolates are initially formed at high concentration before undergoing transformation is attributed to a phenomenon resembling the memory effect. The three configurationally isomeric triesters could be unique instances involving conformational transformation of purely carbocyclic six-membered rings, where the difference in the mechanisms of protonation and methylation clearly surfaces offering contrast with the thiane systems reported in the literature ${ }^{13}$, where a sulphur atom is part of the six-membered ring and where conformational trasfromation is prevented by an anchoring tert-butyl group.
Future work on these lines is to compare and contrast the behaviour of the triesters $4 \mathbf{a}, \mathbf{4 b}$ and $\mathbf{4 c}$ on treatment with trityllithium and tritylpotassium with what we seen with tritylsodium. The interpretations presented in this paper have been based entirely on qualitative but logical terms. Newer techniques of molecular mechanics (for modelling the conformational preferences of the triesters $\mathbf{4 a}, \mathbf{4 b}$ and $\mathbf{4 c}$ ) or those based on quantum chemical bonding theory, such as $a b$ initio (or density function theoretical) methods (for calculating the free-energy difference between the $\mathbf{4} \mathbf{a}^{\prime}$ - and the $\mathbf{4} \mathbf{c}^{\prime}$-enolates) may provide quantitative affirmation of the interpretations. An example would be to answer why the former transforms into the latter. These projects are for all those interested to undertake in the future.

1. Balasubrahmanyam, S. N., The 'C-11 Acid' and the stereochemistry of abietic acid. Resonance, 2015, 20, 217-233; http://www.ias.ac.in/article/fulltext/reso/020/03/0217-0234.

2. Ruzicka, L. and Meyer, J., Höhere Terpenverbindungen XVII. Über die gelinde Einwirkung von Kaliumpermanganat auf die Abietinsäure. Helv. Chim. Acta, 1923, 6, 1097-1108; doi: 10.1002/hlca.192300601128; Ruzicka, L., Meyer, J. and Pfeiffer, M., Höhere Terpenverbindungen XXVI. Über den Abbau der Abietinsäure mit Kaliumpermanganat und Ozon. Helv. Chim. Acta, 1925, 8, 637-650; doi:10.1002/hlca.19250080191; Ruzicka, L., Goldberg, M. W., Huyser, H. W. and Seidel, F., Höhere Terpenverbindungen XLVIII. Über die Konstitution der durch Oxydation der Abietinsäure gewonnenen Tricarbonsäuren $\mathrm{C}_{11} \mathrm{H}_{16} \mathrm{O}_{6}$ und $\mathrm{C}_{12} \mathrm{H}_{18} \mathrm{O}_{6}$. Ein Beitrag zur Kenntnis des Kohlenstoffgerüstes der Abietinsäure. Helv. Chim. Acta, 1931, 14, 545-570; doi: 10.1002/hlca.19310140154; Ruzicka, L., de Graaff, G. B. R., Goldberg, M. W. and Frank, B., Polyterpene und polyterpenoide LXXI. Über den oxydativen Abbau der Dextro-Pimarsäure. Helv. Chim. Acta, 1932, 15, 915-923; doi:10.1002/hlca.19320150196; Ruzicka, L. and Bernold, E., Zur Kenntnis der Diterpene. (48. Mitteilung). Über den Abbau der Agathen-disäure mit Kaliumpermanganat. Helv. Chim. Acta, 1941, 24, 931-939, doi:10.1002/ hlca.194102401111.

3. Barton, D. H. R. and. Schmeidler, G. A., The application of the method of electrostatic energy differences. Part I. Stereochemistry of the diterpenoid resin acids. J. Chem. Soc., 1948, 1197-1203; doi:10.1039/JR9480001197.

4. Ruzicka, L., The isoprene rule and the biogenesis of terpenic compounds. Cell. Mol. Life Sci., 1953, 9, 357-367; doi:10.1007/ BF02167631.

5. Banerjee, D. K., Balasubrahmanyam, S. N. and Ranganathan, R., Syntheses of the trans, meso- and racemic C-11 acids, degradation products of diterpene acids. J. Chem. Soc. (C), 1966, 1458-1467; doi:10.1039/J39660001458; Banerjee, D. K. and Balasubrahmanyam, S. N., The synthesis of the trans, trans and cis, trans isomers of the C-11 acid, degradation products of abietic and agathic acids. Bull. Natl. Inst. Sci. India, 1968, 37, 114-124.

6. Linstead, R. P. and Millidge, A. F., Fused carbon rings. Part IX. The synthesis of stereoisomeric 1-methyl-cyclohexane-1:2dicarboxylic acids and of various methyl cyclo hexane carboxylic acetic acids. The influence of the angular methyl group on the stability of their anhydrides. J. Chem. Soc., 1936, 478-486; doi:10.1039/JR9360000478.

7. Balasubrahmanyam, S. N. and Balasubramanian, M., On the conformations of isomeric trimethyl 1-methylcyclohexane-1,2,3tricarboxylates. J. Chem. Soc. (B), 1970, 212-217; doi:10. 1039/J29700000212. 


\section{RESEARCH ACCOUNT}

8. Belostotskii, A. M., Conformational Concept for Synthetic Chemist's Use: Principles and in Lab Exploitation, World Scientific: Singapore, 2016, ISBN: 978-981-281-409-8.

9. Zook, H. D. and Russo, T. J., Chemistry of enolates. iv. Solvents for enhanced carbanion activity, J. Am. Chem. Soc., 1960, 82, 1258-1259 doi:10.1021/ja01490a064; Zaugg, H. E., Horrom, B. W. and Borgwardt, S., Specific solvent effects in the alkylation of enolate anions. I. The alkylation of sodiomalonic esters with alkyl halides, J. Am. Chem. Soc., 1960, 82, 2895-2903; doi:10.1021/ ja01496a055; Zaugg, H., Horrom, B. and Borgwardt, S., Additions and corrections - specific solvent effects in the alkylation of enolate anions. I. The alkylation of sodiomalonic esters with alkyl halides. J. Am. Chem. Soc., 1960, 82, 6429-6431, doi:10.1021/ ja01509a632; Raban, M. and Haritos, D. P., NMR studies of enolate anions. 6. A carbon-13 NMR study of alkali metal chelation by 3-alkylacetylacetonates. J. Am. Chem. Soc., 1979, 101, 51785182; doi:10.1021/ ja00512a011; Parker, A. J., The effects of solvation on the properties of anions in dipolar aprotic solvents. Q. Rev. Chem. Soc., 1962, 16, 163-187; doi.org/10.1039/ QR9621600163; Jayaraj, K., Studies in the stereochemistry of alkylation - importance of gegenion co-ordination, $\mathrm{Ph} \mathrm{D}$ thesis, Indian Institute of Science (IISc), Bengaluru, 1981, p. 20

10. Balasubrahmanyam, S. N. and Jayaraj, K., Syn-axial and counterion coordination factors in the methylation of 6-membered cyclic esters. Indian J. Chem. (B), 2003, 42, 1098-1110.

11. Kawabata, T., Kawakami, S. and Fuji, K., Enantioselective $\alpha$ allylation of a phenylalanine derivative under the control of aggregation of a chiral nonracemic enolate. Tetrahedron Lett., 2004,. 43, 1465-1467.

12. Cram, D. J., Fundamentals of Carbanion Chemistry, Academic Press, New York, USA, 1965, pp. 85-105; 138-158.

13. Chaissaing, G., Lett, R. and Parquet, A., Convincing evidence that the alkylation stereochemistry of cyclic $\alpha$-lithio sulfoxides is governed by their chelated structure, Tetrahedron Lett., 1978, 471-474; Lett, R., Chaissaing, G. and Marquet, A., Structure of sulfurstabilized carbanions. A ${ }^{13} \mathrm{C}$ NMR study of some $\alpha$-lithio-sulfoxides and sulfones. J. Organomet. Chem., 1976, 111, C17; https://doi.org/10.1016/S0022-328X(00)87137-5

14. Narasimha Bharathi, S., Stereochemical investigations in chiral ethyl esters, Ph D thesis, IISc, Bengaluru, 1981, pp. 56-57; 96-97.

15. Johnson, F. and Malhotra, S. K., Steric interference in allylic and pseudo-allylic systems. I. Two stereochemical theorems. J. Am.
Chem. Soc., 1965, 87, 5492-5493; Steric interference in allylic and pseudo-allylic systems. II. Stereochemistry of exocyclic enolate anion protonation. J. Am. Chem. Soc., 1965, 87, 54935494; doi:10.1021/ja00951a046 and doi:10.1021/ja00951a047; Johnson, F., Allytic strain in six-membered rings. Chem. Rev., 1968, 68, 375-413; doi:10.1021/cr60254a001; Johnson, F. and Dix, D. T., Allytic (1,3) strain. Defence. J. Am. Chem. Soc., 1971, 93, 5931-5932; doi:10.1021/ja00751a077.

16. Letsinger, R. L., Formation of optically active 1-methylheptyllithium. J. Am. Chem. Soc., 1950, 72, 4842; doi:10.1021/ ja01166a538

17. March, J., Advanced Organic Chemistry-Reactions, Mechanisms and Structure, Wiley Eastern, New Delhi, 1986, 3rd edn, pp. 156; $517-518$.

18. Zhao, H., Hsu, D. C. and Carlier, P. R., Memory of chirality: an emerging strategy for asymmetric synthesis. Synthesis, 2005, 1-16; doi:10.1055/s-2004-834931; Wolf, C., Dynamic Stereochemistry of Chiral Compounds: Principles and Applications, Royal Society of Chemistry, London, 2008; doi:10.1039/9781847558091.

19. Kawabata, T., Suzuki, H., Nagae, Y. and Fuji, K., Achiral nonracemic enolate with dynamic axial symmetry: direct asymmetric $\alpha$-methylation of $\alpha$-amino acid derivatives. Angew. Chem. Int. Ed. Engl., 2000, 39, 2155-2157; doi:10.1002/1521-3773(20000616).

ACKNOWLEDGEMENTS. The aim of this study has been furtherance of earlier interpretations of phenomena associated with the behaviour of $\mathrm{C}-3$ enolates derived from configurationally different 1 methylcyclhexane-1,2,3-tricarboxylic methyl esters. Interesting aspects of this behaviour were observed by meticulously conducted experiments starting with the synthesis, chromatographic separations and characterization of materials of closely related structure, and allied work, carried out in the Department of Organic Chemistry, Indian Institute of Science by Drs M. Balasubramanian, K. Jayaraj and S. Narasimha Bharathi. I am grateful to them. The complete interpretation is the result of research conducted by the present author, who alone is responsible for any lacunae that may remain.

Received 25 June 2018; accepted 18 March 2019

doi: $10.18520 / \mathrm{cs} / \mathrm{v} 116 / \mathrm{i} 12 / 1975-1986$ 